providing information on how to reduce the risks of acquiring and transmitting the virus. ${ }^{11}$ Pre-test counselling also aims at ensuring fully informed consent. Although detailed discussion before testing is appropriate when a woman is particularly at risk of infection, for most women at very low risk the situation is different. Antenatal care is already complicated enough by explanations of routine tests, specific prenatal diagnostic tests, health messages, procedures, and relevant symptoms to report that patients are in danger of being overloaded with information. When the probability of a woman being infected with HIV is very low it seems unreasonable to conduct mandatory intensive counselling. Instead, written material should be available and a brief discussion with the midwife or obstetrician should take place. Questions from the patient may lead to a longer discussion, but we believe that women who wish to be tested should be exposed to a fairly simple procedure which nevertheless ensures explicit consent. This opinion has support from ethical groups ${ }^{12}$ and others with experience of screening clinics. ${ }^{13}$ Perhaps greater emphasis than currently exists should be placed on HIV testing at pre-pregnancy, well woman, and family planning clinics. Likewise, the offer of an HIV test to women who have an abortion should be considered.

An obstetric centre's principal objective should be to serve the needs of its pregnant population. Even in centres that promote universal testing the value and success of such programmes should be evaluated not only by measuring the uptake of HIV testing but also by seeking the views of pregnant women and staff. It is important that the emphasis should be on access to testing so that women can exercise choice.

The Department of Health's guidelines should reduce the disjointed nature of current procedures.' They provide a useful framework for local decision making about testing policy and emphasise the need for better data collection, access to information, and interdisciplinary collaboration, thus enabling health authorities to make decisions which are truly informed.

D J GOLDBERG

Honorary senior lecturer in HIV/AIDS epidemiology Communicable Diseases (Scotland) Unit,

Ruchill Hospital,

Glasgow G20 9NB

F D JOHNSTONE

Senior lecturer in obstetrics and gynaecology

Department of Obstetrics and Gynaecology,

University of Edinburgh,

Edinburgh EH3 9EW

1 Department of Health. Guidelines for offering voluntary named HIV antibody testing to women receiving antenatal care. London: $\mathrm{DoH}, 1992$. (PUCO(92)5.)

2 Moore RD, Hidalgo J, Sugland BW, Chaisson RE. Zidovudine and the natural history of the acquired immunodeficiency syndrome. N Engl I Med 1991;324:1412-6.

3 Graham NMH, Zeger SL, Park LP, Phair JP, Detels R, Vermund SH, et al. Effect of zidovudine and Pneumocystis carinii pneumonia prophylaxis on progression of HIV-1 infection to AIDS Lancet 1991;338:265-9.

4 Leoung GS, Feigal DW, Montgomery AB, Corhery K, Wardlaw L, Adams M, et al. Aerosolised pentamidine for prophylaxis against Pneumocystis carinii pneumonia. N Engl f Med 1990;323 769-75.

5 Dunn DT, Newell ML, Ades AE, Peckham CS. Risk of human immunodeficiency virus type 1 transmission through breast feeding. Lancet 1992;340:585-8.

6 Peckham CS, Tedder RS, Briggs M, Ades AE, Hjelm M, Wilcox AH et al. Prevalence of maternal HIV infection based on unlinked anonymous testing of newborn babies. Lancet 1990;335:516-9.

7 Gill ON, Adler MW, Day NE. Monitoring the prevalence of HIV. BMF 1989;229:1295-8.

8 Goldberg D, Mackinnon H, Smith R, Patel NB, Scrimgeour JB, Inglis JM, et al. Prevalence of human immunodeficiency virus among childbearing women and those undergoing termination human immunodeficiency virus among

9 Working Group on HIV Testing of Pregnant Women and Newborns. HIV infection, pregnant women and newborns. $\mathscr{F} A M A 1990 ; 264: 2416-20$.

10 Ades AE, Parker S, Berry T, Holland FJ, Davison CF, Cusi HD, et al. Prevalence of maternal HIV-1 infection in Thames regions, results from anonymous unlinked neonatal testing. Lancer 1991;337:1562-5.

11 Holman S, Sutherland A, Berthaud M, Cancellier F, Moroso S. Prenatal HIV counselling and testing. Clin Obstet Gynaecol 1989;32:445-55.

12 Boyd KM. HIV infection: the ethics of anonymised testing and of testing pregnant women. Ethics 1990;16:173-8.

13 McCarthy KH, Johnson MA, Studd JWW. Antenatal HIV testing. Br f Obstet Gynaecol 1992;99:867-8.

\title{
Where are the women in studies of coronary heart disease?
}

\author{
White middle aged men are not necessarily representative of all humankind
}

Coronary heart disease has traditionally been regarded as a disease of men, but it is also the leading cause of death and an important cause of morbidity and disability in women. Each year in Britain about 100000 men and 80000 women die of the disease.

Most research into the causes, prevention, diagnosis, and treatment of coronary heart disease has been conducted in men-more specifically, white middle aged men. Reasons for this include the well recognised excess of coronary heart disease among men and the easier accessibility of male populations to study. Although these studies have provided much insight into coronary heart disease, the dearth of data in women has caused concern. ${ }^{12}$

Medical practice relies on applying general principles to individual patients. Generalising findings from men to women may, however, not always be appropriate as the effects of some interventions may differ either qualitatively or quantitatively between men and women. These interventions include coronary artery bypass grafting, dietary manipulation or lipid lowering drugs for hypercholesterolaemia, and oestrogen replacement treatment.

Concentrating research on white middle aged men may have ramifications beyond the simple lack of data on the effects of interventions in women and other age or ethnic groups. With the increasing constraints on health services and the emphasis on using only diagnostic procedures and interventions that have been fully evaluated, there may be increasing pressures to exclude population groups who have not been studied from access to particular interventions because of lack of proved benefit. More subtly, research may reinforce the idea that coronary heart disease is a mainly male concern and may result in the relative neglect of the condition in women.

Several American studies have shown a gender bias in the management of coronary heart disease. Women with symptoms are less likely than men to be referred for investigations and treatment or are diagnosed and treated later in the course of their illness. ${ }^{34}$ Later diagnosis, referral, and treatment may result in a worse prognosis, including higher mortality and slower recovery. ${ }^{5}$ Some of these differences may be due to the way that health care is paid for in the United States-insurance plans may disadvantage nonworking women.

Although the NHS is meant to treat patients according to need, a paper in this week's journal by Petticrew and colleagues suggests that the management of coronary artery disease differs by gender in Britain (p 1164).${ }^{6}$ Having looked at hospital discharge data from North West and South West 
Thames regions, the authors report that, among all patients with a main diagnosis of angina or chronic ischaemia, men were significantly more likely than women to receive surgical treatment. None of the several possible clinical explanations satisfactorily explains the differences, and the true explanation is more likely to arise from a system of beliefs that leads to women with disease being referred for investigation and treatment much less commonly than men. Although the well known excess of coronary heart disease in men might explain this bias, substantial evidence exists that such different patterns of referral and treatment apply in other conditions such as renal failure in which no such male preponderance exists.

This study raises questions about a systematic difference in the treatment received by men and women in Britain which lacks any clinical justification. Instead, treatment seems to reflect the different attitudes that doctors, and possibly patients, have to the risks and benefits of intervening in coronary heart disease in men and women. The authors suggest that these attitudes may be influenced by the fact that most studies of prevention and treatment of cardiovascular diseases (and indeed many other conditions) have been conducted exclusively on male populations. They point out that whether women's reduced access to surgery necessarily implies disadvantage in Britain is unclear: we do not have sufficient comparative information to make sensible judgments.

There is now a consensus for more studies in women and, indeed, further studies in overlapping populations such as elderly people and ethnic minorities. ${ }^{17}$ We need to know whether the present recommendations for preventing, investigating, and treating coronary heart disease, which are largely based on the experience in white middle aged men, are equally appropriate in women, elderly patients, and other ethnic groups. We need studies to identify differences in the recognition of symptoms, the results of diagnostic tests, and referral rates and to assess the impact of any such differences on prognosis and recovery from coronary heart disease. Trials of specific interventions for coronary heart disease such as oestrogen replacement treatment and dietary or pharmacological interventionsin women are also required.

How can this be taken further? The Office of Research on Women's Health was set up by the National Institutes of Health in the United States to address the inequality of women in health research and care; a 10 year, $\$ 500 \mathrm{~m}$ research initiative that started in 1991 includes clinical trials and observational studies as well as research on methods to promote healthy behaviour in women. Do Britain's women deserve something similar? The deficiency of data on risk factors, prevention, and treatment of heart disease in women in Britain is even greater than in the United States despite the fact that British women have one of the highest rates of coronary heart disease worldwide.

Arguments that we may be duplicating the American efforts and, given the constraint on resources for research in Britain, should await the findings from these studies are easily countered. Just as generalising findings from men to women is difficult so too is extrapolating findings from one country to another with different distributions of risk factors, incidences of disease, secular trends, and health care organisation. We need locally relevant data.
Findings from any one study in any one place are never completely conclusive: even if biological mechanisms are universal, differing prevalences of risk factors, changing natural courses of disease, and the ways that interventions are applied may profoundly influence the absolute benefits from interventions tested under the strictly controlled conditions of a particular research study. This implies the need not only for definitive trials but also for continually monitoring and evaluating the impact of practices in changing circumstances. Problems, priorities, and optimal solutions may differ from place to place.

As a first step women should be included in future research studies unless good reason exists for excluding them. More formally, we need an organisational framework to identify the gaps in our knowledge that inhibit our ability to recommend best clinical practice and prioritise research needs. Britain's NHS research and development programme under the direction of Professor Michael Peckham may provide the framework for addressing the lack of information not only on coronary heart disease in women but also on other conditions and in other previously neglected groups. High among its list of research priorities is likely to be the need for better evidence on which to base our policies for prevention and health care in women. Funding initiatives within the research and development programme or encouragement from other research funding bodies may stimulate such research.

The test of medical research will be its impact on influencing and improving practice and ultimately, health outcome. Inadequate understanding of the process of disease in women and how and why it may differ from that in men may result not only in inappropriate interventions in women, whether in preventing or in treating disease, but also in limited understanding of the pathophysiology of disease in humans in general. While more research in women may directly benefit women, it could provide further benefits to men.

KAY-TEE KHAW

University of Cambridge School of Professor in clinical gerontology

Clinical Medicine,

Addenbrooke's Hospital,

Cambridge CB2 2QQ

1 Healy B. The Yentl syndrome. N Engl F Med 1991;325:274-6.

2 Gurwitz JH, Col NF, Avorn J. The exclusion of the elderly and women from clinical trials in myocardial infarction. fAMA 1992;268:1417-22.

3 Ayanian JZ, Epstein AM. Differences in the use of procedures between women and men hospitalized for coronary heart disease. NEngl f Med 1991;325:221-5.

4 Steingart RM, Packer M, Hamm P, Coglianese ME, Gersh B, Geltman EM, et al. Sex differences in the management of coronary artery disease. $N$ Engl $f$ Med 1991;325:226-30.

5 Khan SS, Nessim S, Gray R, Czer LS, Chaux A, Matloff J, et al. Increased mortality of women in coronary bypass surgery: evidence for a referral bias. Ann Intern Med 1990;112:561-7.

6 Petticrew M, McKee M, Jones J. Coronary artery surgery: are women discriminated against? $B M$ 1993;306:1164-6.

7 Fair of face and sick at heart [editorial]. Lancet 1991;338:1366-7.

\section{Correction}

\section{Short acting benzodiazepines}

Owing to a printer's error two references were omitted from this editorial by Michael C O’Donovan and Peter McGuffin (10 April, pp 945-6):

15 Bayer AJU, Bayer EM, Pathy MSJ, Stoker MJ. A double blind controlled study of chlormethiazole and triazolam as hypnotics in the elderly. Acta Psychiatr Scand 1986;73(suppl 329):104-11.

16 Bliwise DL, Seidel WF, Cohen SA, Bliwise NG, Dement WC. Profile of mood states change during and after 5 weeks of nightly triazolam administration. J Clin Psychiatry 1988;49:349-55. 